\title{
O IMPACTO DA FORMAÇÃO DE PROFESSORES DE INGLÊS REALIZADA NA UNIVERSIDADE FEDERAL DO PIAUÍ: ANÁLISE DAS ESCOLHAS PROFISSIONAIS DE ALGUNS EGRESSOS DO CURSO DE LETRAS INGLÊS
}

\author{
EL IMPACTO DE LA FORMACIÓN DE PROFESORES DE INGLÉS REALIZADA EN \\ LA UNIVERSIDAD FEDERAL DE PIAUÍ: ANÁLISIS DE LAS DECISIONES \\ PROFESIONALES DE ALGUNOS EGRESOS DEL CURSO DE LETRAS INGLÉS \\ THE IMPACT OF ENGLISH TEACHERS' EDUCATION PERFORMED AT THE \\ FEDERAL UNIVERSITY OF PIAUÍ: AN ANALYSIS OF THE PROFESSIONAL \\ CHOICES OF SOME GRADUATED STUDENTS FROM THE ENGLISH LANGUAGE \\ MAJOR
}

\author{
Beatriz Gama RODRIGUES ${ }^{1}$
}

RESUMO: Neste artigo, apresento relatos sobre as escolhas profissionais de alguns egressos do Curso de Letras Inglês da Universidade Federal do Piauí. Em nosso curso, temos o objetivo de formar professores de língua inglesa capazes de preencher as insuficiências de profissionais devidamente habilitados e capacitados para atuar nas redes municipal, estadual e particular de ensino do Estado do Piauí, prestando um serviço educacional de qualidade, fundamentados numa visão de língua estrangeira mais ampla, não somente como um fenômeno linguístico, mas como uma ferramenta que possibilite o engajamento discursivo de seus usuários, concebendo a linguagem como um ato ou prática social. Com o objetivo de conhecer as experiências profissionais de egressos do curso, elaborei algumas questões para que alguns deles fizessem algumas reflexões sobre suas escolhas, desafios e alegrias. Foram selecionados egressos que estão em escolas públicas e particulares, na capital e no interior do Estado, para conhecermos um pouco mais sobre seus contextos e as razões de suas escolhas. Acreditamos que essas análises nos permitirão refletir também sobre o papel que nosso curso tem, e como podemos auxiliar os nossos alunos a se prepararem para serem profissionais do ensino-aprendizagem de línguas críticos e competentes.

PALAVRAS-CHAVE: Formação de professores de línguas. Escolhas profissionais. Egressos.

RESUMEN: En este artículo, presento algunos relatos acerca de las decisiones profesionales de algunos egresos del Curso de Letras Inglés de la Universidad Federal de Piauí. En nuestro curso, tenemos el objetivo de formar profesores de lengua inglesa capaces de llenar las insuficiencias de profesionales debidamente habilitados y capacitados para actuar en las redes municipal, estadual y privada de enseñanza del Estado del Piauí, prestando un servicio educacional de cualidad, basados en una visión de lengua extranjera aún más amplia, no solamente como un fenómeno lingüístico, pero como una herramienta que posibilite el envolvimiento discursivo de sus usuarios, concibiendo el lenguaje como un acto de práctica social. Con el objetivo de conocer las experiencias profesionales de egresos del Curso, elaboré

${ }^{1}$ Universidade Federal do Piauí (UFPI), Teresina - PI - Brasil. Professora Adjunto I de Língua Inglesa, Assessora Internacional. Coordenação de Letras Estrangeiras. ORCID <https://orcid.org/0000-0001-8802-8320>. E-mail: beatriz@ufpi.edu.br 
algunas cuestiones para que algunos de ellos hicieron algunas reflexiones acerca de sus decisiones, desafios y alegrías. Fueron seleccionados egresos que están en escuelas públicas y privadas, en la capital y en el interior del Estado, para que conozcamos un poco más sobre sus contextos y las razones de sus opciones. Creemos que esos análisis permitirán que nosotros reflexionar también sobre el papel que nuestro curso tiene, y cómo podemos auxiliar nuestros alumnos a prepararse para ser profesionales de la enseñanza-aprendizaje de lenguas críticos y competentes.

PALABRAS CLAVE: Formación de profesores de lenguas. Decisiones profesionales. Egresos.

ABSTRACT: In this article, I present some narratives about professional choices from some graduates from the English Language Major from the Federal University of Piauí. In our program, we aim at educating English teachers able to fulfill the insufficiencies of professionals who are appropriately qualified to work in the municipal, state and private teaching networks of education in the state of Piauí, providing an educational service of good quality, based on a broader vision of foreign language, not only as a linguistic phenomenon, but as a tool that enables discursive engagement of its users, conceiving language as a social act or practice. In order to know the professional experiences of some of our graduates, I have elaborated some questions for them to reflect about their choices, challenges and delights. Some graduates selected were working in public and private schools, in the capital and in the interior of the State, to know a little more about their contexts and the reasons for their choices. We believe that these analyzes will help us to reflect also about the role our program has, and how we can help our students to prepare to become critical and competent professionals of languages teaching-learning.

KEYWORDS: Language teachers' education. Professional choices. Graduates.

\section{Introdução}

Ao ser convidada para escrever este artigo para o Dossiê "Concepções teóricometodológicas para o ensino e a aprendizagem de línguas estrangeiras: contextos e perspectivas", resolvi fazer uma pesquisa para descobrir o que estaria acontecendo com alguns dos egressos do nosso Curso de Letras Inglês na Universidade Federal do Piauí (UFPI). Muitas vezes, perdemos totalmente o contato com os nossos queridos alunos após a formatura. As redes sociais nos proporcionam algumas notícias, mas geralmente são mais relacionadas à sua vida pessoal e desconhecemos se estão atuando como professores de inglês e quais seriam suas conquistas. Acredito que descobrir o que nossos egressos estão fazendo é a melhor forma de avaliar os resultados da formação de professores de línguas que estamos proporcionando em nossas universidades. Decidi, desta maneira, pesquisar se alguns alunos estariam lecionando em escolas públicas ou em outros estabelecimentos: escolas particulares ou cursos livres de 
idiomas e quais as razões para essas escolhas. Como sou professora de inglês em um curso de Letras em uma universidade federal, incentivo meus alunos, futuros professores, a trabalharem também em escolas públicas. Isso se deve, principalmente, à conscientização que a maior parte dos alunos não têm acesso a escolas particulares ou a cursos de idiomas e, também, por acreditar que é possível sim começar a aprender uma língua estrangeira na escola pública, desde que os principais atores do processo ensino-aprendizagem estejam motivados e dispostos a atingir seus objetivos da melhor forma possível.

Como trabalho no Piauí há quase dez anos, conheço um pouco da realidade do Estado e sei que temos necessidade de formar professores de línguas (no meu caso, inglês) que estejam realmente auxiliando seus alunos a aprender, porque, em muitos casos, será muito difícil ter acesso a outras formas de aprendizagem. A UFPI somente oferece o curso de Letras Inglês presencial na capital do estado, Teresina. A Universidade Estadual do Piauí (UESPI) tem uma oferta maior: há cursos de Letras Inglês nas cidades de Floriano, Piripiri e Parnaíba, além de Teresina. Tanto a UFPI quanto a UESPI oferecem o curso de Letras Inglês na modalidade a distância desde 2011. Entretanto, conforme notícias veiculadas na imprensa local, infelizmente, temos conhecimento que alguns desses cursos (tanto presenciais quanto a distância, principalmente no interior do estado) têm várias carências, tais como falta de professores efetivos, bibliotecas e equipamentos tecnológicos. Em decorrência desse limite na formação de professores de língua inglesa no estado do Piauí, além de outros fatores como falta de maiores investimentos na educação, no turismo e na indústria, há várias cidades onde não há professores de inglês com formação em Letras. Tive acesso a esses problemas por ter feito uma atividade de formação continuada com professores de língua inglesa da Rede Estadual em 2016, por ter auxiliado no desenvolvimento do Projeto Político Pedagógico do Curso de Letras Inglês a distância da UFPI em 2009, e por ter sido coordenadora do curso de Letras Inglês do Plano Nacional de Formação de Professor da Educação Básica (PARFOR) de 2012 a 2014.

Por meio de conversas informais com professores e estudantes, fiquei sabendo de várias cidades do Piauí onde não há cursos livres de idiomas, com acesso limitado ou precário a internet, e cujos professores de inglês não têm formação em Letras. Acredito que os professores de línguas dessas cidades enfrentam desafios ainda maiores do que os que lecionam na capital do estado e, portanto, precisam receber uma formação inicial nas instituições de ensino superior de alta qualidade a fim de estarem mais preparados para a realidade que enfrentarão e poderem lutar por melhores condições para exercer sua profissão.

Para poder escrever este artigo, selecionei seis egressos do Curso de Letras Inglês da UFPI e lhes pedi, por meio de uma rede social, que respondessem a algumas perguntas. Esses 
professores foram escolhidos porque, de alguma maneira, se destacaram durante o período em que estudaram conosco, seja por demonstrarem um maior interesse em seu aperfeiçoamento profissional e acadêmico, seja por serem oriundos de escolas públicas e terem conseguido vencer inúmeros desafios durante a formação inicial. Além disso, sabia que dois deles eram professores em escolas públicas e uma em escola particular e queria conhecer um pouco mais sobre a realidade que estariam enfrentando. Também tinha conhecimento que os outros três eram professores em cursos livres de idiomas em Teresina e considerei de interesse saber porque não haviam buscado também escolas públicas.

Com o intuito de embasar as análises realizadas, na seção seguinte, desenvolvo algumas reflexões sobre a formação inicial de professores de línguas e o processo ensino-aprendizagem em escolas brasileiras.

\section{Formação de professores de língua inglesa e o processo ensino-aprendizagem em escolas brasileiras}

O curso de Letras Inglês da UFPI tem a duração de quatro anos. Nesse período, procuramos desenvolver as habilidades que serão necessárias para o exercício profissional dos egressos, aperfeiçoando suas competências linguísticas, culturais e relacionadas ao ensinoaprendizagem de línguas. Os professores formadores são essenciais para auxiliar a promover um aperfeiçoamento no processo de formação de professores, buscando atender às necessidades de aprendizagem individuais dos seus alunos, futuros professores. É essencial a participação efetiva dos professores dos cursos de formação nesse desafio, almejando o seu aperfeiçoamento constante, refletindo constantemente sobre sua prática pedagógica, buscando junto aos alunos formas de atingir mais eficientemente seus objetivos; enfim, formando um grupo coeso e consciente de seu objetivo maior: a melhor formação do profissional de língua inglesa. Não pretendemos diminuir o papel que o aluno desempenha nesse processo, é mais do que provado o quanto o aprendiz é responsável pela sua aprendizagem; todavia, acreditamos que o corpo docente tem uma grande responsabilidade pelo sucesso (ou não) dessa nova empreitada.

Celani (2001) formula a seguinte pergunta: “Qual é o perfil do profissional que queremos, de que o país precisa?’. Concordo com a resposta dada pela autora:

Não é, por certo o 'robô orgânico' (mero reprodutor), 'operado por um gerente' (seu coordenador? As normas impostas pelo MEC, pelas Secretarias de Educação, pela escola? As editoras?) 'por meio de um controle remoto' (técnicas e receitas prontas, fórmulas, materiais didáticos à prova de professor?), mas, 'um ser humano independente', com sólida base na sua 
disciplina, (a língua que ensina), mas com 'estilo característico de pensar' (visão de ensino como desenvolvimento de um processo reflexivo, contínuo, comprometido com a realidade do mundo e não mera transmissão de conhecimento).

Acredito que os profissionais que trabalham nas Instituições de Ensino Superior na formação de professores têm como desempenhar um papel positivo para que esse perfil se torne verdadeiro. O professor formador pode ajudar a desenvolver esse perfil de profissionais do ensino de línguas para que seja aperfeiçoado o ensino-aprendizagem de línguas estrangeiras, quebrando o círculo vicioso citado por Paiva (2003, p. 77):

[...] os cursos de Letras não formam bons professores, esses professores não têm a competência necessária para ensinar a língua, o ensino básico não oferece um ensino de LE de qualidade e seus egressos procuram o curso de Letras para se transformarem em professores no prazo de três anos.

Devo afirmar que, apesar de reconhecer que essa imagem negativa generalizada faça parte do repertório de muitas pessoas, não acredito que os cursos de Letras, em geral, não formem bons professores. Há vários profissionais e pesquisadores empenhados em buscar mudanças e o aperfeiçoamento da formação de professores formados pelos cursos de Letras, portanto, acredito que podemos, sim, quebrar o círculo vicioso mencionado por Paiva. Assim, estaremos ajudando a formar uma imagem mais positiva do professor de língua estrangeira e, muito mais importante, auxiliando na ressignificação do processo ensinoaprendizagem de línguas no Brasil.

Esse perfil de professor, o qual também considero ideal e apresento aos alunos do curso de Letras, foi definido por Fullan (1993) e resumido por Celani (2001):

O professor do futuro deve

1. Empenhar-se em afetar a vida de seus alunos (objetivo moral).

2. Aprofundar o conhecimento pedagógico (conhecimento mais sofisticado sobre ensinar e aprender).

3. Conscientizar-se sobre os amplos problemas de política educacional e desenvolvimento social.

4. Trabalhar de modo interativo e colaborativo.

5. Aprender a trabalhar em novas estruturas - redes de aprendizagem.

6. Desenvolver o hábito e as habilidades de indagação e aprendizagem contínuas.

7. Mergulhar nos mistérios, nos altos e baixos da complexidade dinâmica do processo de transformação.

Penso que esse profissional é construído aos poucos, com muita reflexão, diálogo, pesquisa e paixão pelo ensino e pelo próximo. A formação de professores em pré-serviço reflexivos pode ser praticada nos cursos de Letras com o objetivo de desenvolver essa característica nos alunos a fim de que eles estejam sempre refletindo sobre sua prática, quando 
estiverem em suas salas de aulas. Essa visão também é exposta na seguinte afirmação de Freire, ao defender a formação permanente do professor:

A responsabilidade ética, política e profissional do ensinante lhe coloca o dever de se preparar, de se capacitar, de se formar antes mesmo de iniciar sua atividade docente. Esta atividade exige que sua preparação, sua capacitação, sua formação se tornem processos permanentes. [...] Formação que se funda na análise crítica de sua prática (FREIRE, 2001, p. 259-260).

Acredito que essa disposição de refletir constantemente deve ser desenvolvida desde a formação inicial de professores, ainda nos cursos de licenciatura, a fim de que a visão generalizada de que não se aprende línguas estrangeiras nas escolas brasileiras possa ser desmistificada. É evidente que há outras questões que também devem ser consideradas, tais como: quantidade de estudantes nas salas de aula, carga horária disponibilizada para a disciplina, remuneração dos professores, indisciplina dos alunos, infraestrutura das escolas, material didático e outras questões.

Conforme Coelho (2005, p. 14), há uma frustração generalizada por parte dos professores de educação básica da rede pública do Brasil:

Em todas as disciplinas ouvimos os professores queixarem-se das péssimas condições dos estabelecimentos de ensino, da escassez do material didático, da falta de oportunidade para se dar continuidade à sua formação. $\mathrm{O}$ ensino público que antes era reconhecido e escolhido pelas elites do país (BOHN, 2003), hoje se encontra empobrecido e frequentado, quase que somente, pela população menos favorecida.

É triste e paradoxal sabermos que não somente os professores de língua inglesa da educação básica estão frustrados diante do quadro atual expresso acima, mas também os alunos e a sociedade em geral desvalorizam a educação básica. Conforme um relatório publicado pelo Conselho Britânico no Brasil (2014), somente 15\% dos respondentes consideram a educação oferecida pelas escolas públicas como "boa", sendo que 44\% a consideram "mediana", 18\% "ruim" e 19\% "muito ruim". Ainda segundo esse relatório, há uma crença generalizada que os professores de língua inglesa não têm a competência linguística exigida para desenvolver o domínio da língua e que isso faz com que haja poucos profissionais brasileiros que consigam utilizar a língua inglesa eficientemente.

Conforme Perin (2005, p. 3):

Apesar de reconhecerem a importância de saber inglês, os alunos tratam o ensino de língua inglesa na escola pública ora com desprezo, ora com indiferença, o que causa, na maioria das vezes, a indisciplina em salas de aula com o número de alunos acima do ideal para o aprendizado de um novo 
idioma. Esse processo cíclico causa o estresse do professor, mais indisciplina, mais indiferença e, obviamente, a frustração no final do processo. Esse processo também evolui em mão dupla, ou seja, o desinteresse dos alunos faz que os mesmos não percebam a evolução dos conteúdos, o que por sua vez nem sempre ocorre dentro de uma escola com alta rotatividade de professores.

Esse ciclo negativo que envolve professores e estudantes de língua inglesa das escolas públicas brasileiras pode fazer com que os estudantes dos cursos de Letras Inglês das Instituições de Ensino Superior tenham receio de escolher esses estabelecimentos para serem professores. Apesar de reconhecer os problemas citados, acredito ser importante também analisar criticamente as condições de ensino-aprendizagem e principalmente de formação continuada de professores nos cursos livres de idiomas. Assim, na próxima seção, apresento algumas reflexões sobre essa questão.

\section{Algumas questões sobre o processo ensino-aprendizagem de inglês em escolas de línguas}

Ser professor de inglês em uma escola de línguas pode ser muito atrativo para estudantes e egressos dos cursos de Letras talvez por acreditarem que terão mais condições de exercer sua profissão nesses ambientes, pois terão uma quantidade mais adequada de alunos por turma, menos problemas com indisciplina, maior motivação dos alunos, disponibilidade de material didático e outros recursos, tais como artefatos tecnológicos. No entanto, é importante lembrar que as escolas de línguas têm características empregatícias próprias, além de, em geral, metodologias mais inflexíveis com pouco espaço para a autonomia do professor.

Segundo Souza (2013, p. 59), "Em cursos de línguas encontramos comumente dois tipos de profissionais ministrando aulas de inglês, a saber: o professor licenciado e o profissional que leciona, mesmo sem possuir formação acadêmica em Letras. Portanto, há profissionais que são professores de línguas e aqueles que estão professores."

O questionamento que faço é se o fato de empregarem pessoas sem formação acadêmica para serem professores não evidenciaria uma falta de reconhecimento, ou seja, uma desvalorização desses profissionais. Isso é manifestado por Gimenez (2004, p. 172):

[...] embora tenhamos no Brasil condições de considerar o ensino de língua estrangeira como uma profissão, em muitas instâncias este é visto como uma ocupação, isto é, não tem reconhecimento devido. Isto pode ser mais facilmente visível no setor privado que, como empregador, muitas vezes requer apenas o domínio da língua como requisito para 'ser professor'. 
Outra questão que merece uma reflexão crítica é a formação pedagógica continuada disponível nas escolas de línguas. É necessário saber se a formação continuada dos professores é incentivada e desenvolvida nesses estabelecimentos de ensino e de que forma. Conforme Freitas (2010, p. 142):

Outros elementos que podem ser mencionados como índices de precarização do trabalho docente são o pluriemprego, com sua consequente carga horária de trabalho e de ensino fatigante, a ausência ou a insignificância de tempo destinado à preparação de atividades e a reuniões pedagógicas, bem como a carência de recursos materiais.

Outro ponto a ser questionado seria a falta de autonomia ou liberdade para os professores nas escolas de línguas. Muitas vezes, o material didático a ser utilizado é composto por um "manual do professor" que apresenta orientações muito fechadas sobre o ensino de línguas nessa instituição. Esse problema também é mencionado por Freitas (2010, p. 298):

(...) os professores não teriam liberdade de escolha de material didático, que seria determinado pela instituição; os cursos buscariam a uniformidade no trabalho docente; os professores também não teriam liberdade para realizar atividades que fugissem ao manual e aos recursos adotados pela instituição; as aulas seriam preparadas pela coordenação, com tempo determinado para cada atividade.

Essa uniformização existente em algumas escolas de idiomas evidencia a falta de autonomia e a desvalorização dos professores. É importante que essas questões sejam discutidas nos cursos de Letras para que nossos alunos se preparem para realizar um enfrentamento desses aspectos em sua vida profissional. Precisamos fazer com que os profissionais de ensino de línguas sejam valorizados e reconhecidos ao exercerem a docência. A desvalorização dos professores é criticada por Freitas (2010, p. 336):

Essa prática de desvalorização da atividade docente se relaciona com a
tendência de transformação da língua em bem de consumo. O professor é visto
não como agente do processo educativo, mas como um elo da engrenagem
dessa fábrica de produzir aulas de línguas estrangeiras. Como as demais peças,
o professor deve ser facilmente substituível e, para isso, existem as prescrições
detalhadas sobre o andamento das aulas, por meio de um manual do professor.
Numa visão taylorizante do trabalho, entende-se que basta um sujeito ter as
instruções detalhadas, ser treinado e selecionado de acordo com os critérios
da empresa para ser um bom operador. O determinante não é o trabalhador,
mas o método "científico" que deve ser aplicado na sua seleção e no seu
treinamento.

Os cursos livres de idiomas são um dos locais onde os egressos dos cursos de Letras podem exercer sua atividade docente, mas é importante que eles tenham consciência dos aspectos positivos e negativos que podem estar presentes durante seu exercício profissional. 
Assim como nas escolas regulares (sejam elas públicas ou privadas), as escolas de línguas também apresentam desafios que precisam ser enfrentados pelos professores de línguas.

Desta forma, na próxima seção, apresento os participantes desta pesquisa, as questões que lhes foram indagadas e proponho algumas reflexões sobre as respostas desenvolvidas pelos professores, com o objetivo de compreendermos um pouco mais sobre a atuação profissional de egressos do curso de Letras Inglês da UFPI.

\section{Participantes da pesquisa}

Convidei seis egressos do curso de Letras Inglês da UFPI para participarem desta pesquisa respondendo as quatro perguntas abaixo:

1) Por que você está trabalhando em uma escola pública? (Para os dois que estão atuando em escolas públicas)

Por que você está trabalhando em uma escola particular e não em uma escola pública? (Para os outros quatro participantes)

2) Como você se sente como um(a) professor(a) de inglês em uma escola pública? OU Como você se sente como um(a) professor(a) de inglês em uma escola particular?

3) Quais os maiores desafios que você enfrenta?

4) Quais as maiores alegrias que você já teve ou tem?

As perguntas foram desenvolvidas para conhecermos um pouco mais sobre a atuação profissional desses professores: suas escolhas, razões, problemas e alegrias vividas durante a docência.

Abaixo, Quadro 1, apresento algumas informações sobre os participantes²:

Quadro 1 - Participantes

\begin{tabular}{|l|l|c|l|}
\hline \multicolumn{1}{|c|}{ NOME } & IDADE & $\begin{array}{c}\text { TÉRMINO DA } \\
\text { GRADUAÇÃO }\end{array}$ & \multicolumn{1}{c|}{ ATUAÇÃO PROFISSIONAL } \\
\hline Maria & 23 & 2014 & Escola pública no interior do Piauí \\
\hline José & 27 & 2016 & Escola pública no interior do Ceará \\
\hline Paula & 26 & 2013 & Escola particular em Teresina \\
\hline Antônio & 23 & 2015 & Escola de línguas particular em Teresina \\
\hline Ana & 25 & 2014 & $\begin{array}{l}\text { Escola regular particular e escola de línguas } \\
\text { particular em Teresina }\end{array}$ \\
\hline João & 27 & 2012 & Escola de línguas particular em Teresina \\
\hline
\end{tabular}

Fonte: autora

${ }^{2}$ Os nomes dos participantes foram alterados para preservar sua identidade. 
Os dados obtidos por meio das respostas dos participantes foram analisados considerando as suas textualizações conforme a abordagem hermenêutico-fenomenológica (VAN MANEN, 1990). Essa abordagem foi escolhida por associar harmonicamente descrições retrospectivas e interpretação de experiências vividas em sua atuação profissional como professores de língua inglesa.

\section{Análise dos Dados}

\section{Experiências e desafios em escolas públicas}

Os dois participantes que atuam como professores de inglês em escolas públicas justificaram sua escolha por este locus profissional em razão da segurança e da estabilidade financeira que o cargo público lhes oferece. Isso pode ser observado nos trechos abaixo:

Primeiramente por causa da estabilidade financeira, e, mesmo ainda não sendo concursada, estou batalhando para isso e agora está mais perto pois estou trabalhando como contratada através de um concurso que concorri uma vaga, só está faltando a efetivação, mas passei mais de dois anos lecionando nas duas escolas que eu cursei o ensino fundamental e médio sendo celetista e foi muito satisfatório, ou seja, gostaria de deixar bem claro que apesar deste motivo ser o principal, ele não é o mais importante. (Maria)

A escola pública oferece mais flexibilidade ao professor e ainda paga melhor. Além disso, a sonhada estabilidade financeira, auxílio alimentação, plano de saúde, licença para estudo são atrativos. (José)

José ainda menciona a flexibilidade oferecida ao professor pela escola pública e a possibilidade de se afastar para continuar sua formação acadêmica. Considero que esses aspectos são muito importantes na vida profissional e pessoal de professores.

Maria, que é oriunda de uma pequena cidade do interior do Piauí, cursou a educação básica nessa cidade e escolheu voltar para sua escola e região para auxiliar outras pessoas no processo de aprendizagem de língua inglesa. Ela menciona isso no trecho abaixo:

Em segunda instância, venho trabalhando desde o início de 2015, quando me formei, em escolas públicas (é importante mencionar que quando eu estava na universidade passei dois anos e meio participando do Programa de Bolsa de Iniciação à Docência-PIBID, em uma escola pública e considero que esta contribuição foi de suma importância para minha vida profissional, assim como, me ajudou a fazer essa escolha de atuar no ensino público), porque eu também estudei toda minha vida estudantil neste ambiente escolar, e, estou tendo a oportunidade de procurar fazer o ensino e aprendizagem ocorrer de uma forma diferente da qual eu vivenciei, por isso, esta razão é para mim como um combustivel que me impulsiona a fazer parte deste ambiente de 
trabalho buscando fazer minha parte de modo significativo na vida dos públicos alvos que estou me deparando ao longo de quase três anos. (Maria)

A terceira razão apresentada por Maria para lecionar inglês em uma escola pública é o impacto que a sua formação na UFPI teve na sua escolha. Recordo que ela ingressou no curso de Letras com dificuldades linguísticas e conseguiu vencer esses problemas durante os quatro anos do curso. Além disso, o trecho abaixo deixa claro que as discussões sobre o ensinoaprendizagem de línguas realizadas na universidade influenciaram em suas escolhas profissionais:

Outro ponto relevante, é questão de meu curso de graduação ter sido bem proveitoso para mim, onde procurei aproveita-lo da melhor forma possivel, $e$, da maneira como me portei e recebi os conhecimentos que me foram apresentados, creio que eles me tornaram a profissional engajada com um ensino melhor para os discentes, porque, é isto que venho procurando fazer. (Maria)

Os dois participantes (Maria e José) indicaram que estão satisfeitos com a escolha realizada. Os trechos abaixo indicam esses sentimentos:

\begin{abstract}
Me sinto bastante feliz e realizada, porque como disse anteriormente, estou tenho uma oportunidade excelente de estar desempenhando um trabalho diferenciado, pois uma das minhas principais intenções, é mostrar para o alunado a importância de se estudar inglês, mesmo sabendo que é um desafio tamanho, ensinar a língua inglesa em escolas, públicas elou particulares. (Maria)
\end{abstract}

A carga horária é muito pequena. 50 min por semana! Fica difícil obter bons resultados. Mas há uma parcela dos alunos que conseguem êxito. No geral, é agradável, trabalho com música, series, leitura, diálogos. Não me vejo ensinando outra disciplina. (José)

Maria demonstra maior satisfação como professora de inglês em uma escola pública. Fico feliz por saber que ela busca mostrar aos alunos a importância de se estudar inglês, tendo em vista que considero sua tarefa extremamente importante por estar em uma pequena cidade do interior do Piauí.

Por outro lado, apesar de mencionar alguns problemas que enfrenta na escola pública em que trabalha, José deixa claro que está satisfeito porque há alunos que estão tendo sucesso e que se percebe como um professor, já que não consegue se imaginar lecionando outra disciplina.

Os desafios enfrentados pelos dois professores são semelhantes aos relatados por outros profissionais que ministram aulas em escolas públicas brasileiras: superlotação das salas, carga horária insuficiente, professores sem formação na área, falta de materiais didáticos e artefatos tecnológicos e indisciplina. 
Venho enfrentando diversos desafios, os principais são os seguintes: falta de interesse da maioria dos alunos para com a disciplina, salas superlotadas, a indisciplina na sala de aula (a qual está acontecendo não só na matéria de inglês, mas, também nas demais e isso é um pouco frustrante), e a falta de apoio de alguns itens que podem auxiliar/facilitar a aprendizagem, que é a questão da disponibilização de dicionários nas escolas para os alunos utilizarem na sala de aula e também da parte de informática, onde, poderíamos estar usando os computadores nas aulas. (Maria)

A maioria dos estudantes teve aula de inglês no ensino fundamental com um professor sem formação na área. A carga horária pequena atrapalha. E a quantidade de alunos por sala implica na aprendizagem. Sempre mais de 35. (José)

A última pergunta era a que mais me interessava, porque acredito que sempre precisamos ser lembrados e refletir sobre os impactos positivos produzidos em nossa atuação como professores de língua inglesa, especialmente em instituições públicas. A razão para isso é que, em geral, as pesquisas realizadas revelam somente os problemas enfrentados pelos professores.

Maria e José mencionaram alegrias proporcionadas por experiências docentes e relatos dos alunos:

Gosto de ver meus alunos sendo sujeitos críticos, praticando eficazmente o que lhes é ensinado, pois sabemos que a prática é fundamental. Já fiz alguns trabalhos onde eles foram um pouco além, através da independência que lhes permiti. Por exemplo, através de seminários sobre diversos assuntos (special dates around the world, Several topics about William Shakespeare e important singers and some of his/her music) com alunos do ensino médio e de trabalhos com alunos do ensino fundamental, onde eles desenharam os cômodos e objetos que pertencem a uma casa e também nomearam os mesmos, outra atividade que considero significativa foi quando eles fizeram o levantamento dos itens que contém na sala de aula, onde a partir deste grupo de palavras, trabalhei com o uso de flashcards e foi possível trabalhar este tópico de diversas maneiras, através de jogos. Em outras palavras, é muito gratificante ver os alunos respondendo positivamente aos nossos estímulos através de práticas eficazes, sendo protagonista de sua aprendizagem. Outro momento significativo na vida de alguns alunos foi quando tivemos uma conversa com um alemão que é casado com uma mulher da minha cidade natal, os alunos se arriscaram em fazer algumas perguntas em inglês, e eu fiquei muito contente, além disso, foi uma experiência única para os discentes que participaram, pois eles tiveram a oportunidade de ver a língua alvo sendo transmitida/praticada bem de perto, e não ficaram apenas sendo sujeitos passivos, pelo contrário, foram ativos. (Maria)

Fiz amigos, alguns alunos passaram no vestibular. Alguns para cursar inglês e disseram que foi por minha causa. A escola pública cobra papéis que são dos pais, é chato, mas as vezes recompensador. Já ajudei alguns a retomar tratamentos, até em tentativa de suicídio já interferi. Ver os alunos se recuperando e prosseguindo é de emocionar. (José) 
Maria, entre outros fatos, menciona atividades práticas realizadas em suas aulas que proporcionaram oportunidades de aprendizagem significativa a seus alunos, pois relacionaram a língua inglesa com questões presentes em suas vidas (partes da casa, artistas e suas músicas, datas especiais e itens da sala de aula). Além disso, ela também mencionou o momento em que eles conversaram em inglês com um alemão. Ela explicou que essa última atividade foi importante para os alunos perceberem que conseguiam usar a língua inglesa de forma ativa.

José cita as amizades realizadas e a alegria por ter alunos que foram aprovados no vestibular. É interessante que alguns desses alunos escolheram o curso de Letras Inglês e disseram ao professor que ele influenciou essa escolha. Finalmente, foi emocionante saber que ele impactou profundamente as vidas de alguns alunos que estavam passando por graves problemas emocionais.

\section{Experiências e desafios em escolas particulares}

Paula afirma não estar lecionando em escolas públicas por ainda não ter sido aprovada em concursos públicos. Isso é observado no seguinte trecho:

No decorrer do meu curso cheguei a fazer estágios em escolas públicas, $e$ desde que me formei fiz alguns concursos (poucos) para trabalhar em escolas públicas, mas não logrei exito. Acredito que por ter começado muito cedo a dar aula e logo ingressado na escola particular me faltou mais tempo e também dedicação pra estudar pra concurso. (Paula)

Ela se sente feliz como professora de inglês em uma escola particular, pois afirma ter se esforçado muito para conseguir seu cargo. Lembro que Paula tinha muita dificuldade no início do curso de Letras na UFPI e chegou a pensar em desistir por não conseguir acompanhar as aulas, mas conseguiu desenvolver a competência linguística esperada durante o curso.

Por outro lado, apesar de estar feliz na escola particular, ela reconhece o fato de não ter segurança em relação ao seu emprego:

Particularmente, me sinto privilegiada de estar na escola que estou apesar de ter batalhado muito pra isso. Sei que não tenho garantia nenhuma, por ser uma escola privada, mas por ser considerada uma das melhores escolas aproveito cada momento para absorver conhecimentos inerentes à minha profissão. Sou muito feliz como professora de inglês! (Paula)

Em relação aos desafios enfrentados, Paula menciona a dificuldade de se relacionar com os pais dos alunos que parecem tentar interferir na metodologia empregada por ela: 
Hoje um dos maiores desafios que enfrento não é nem tanto com relação aos alunos, que apesar de muitos fazerem curso fora, também existem aqueles com bastante dificuldade. Mas é com relação aos pais que por não buscarem conhecer as estratégias utilizadas em sala criticam bastante e cobram muitas vezes alguns métodos que já não são utilizados na língua inglesa.

Paula relata a alegria de ter feito um curso de língua inglesa em Londres. Percebe-se que ela continua buscando seu desenvolvimento como professora:

A maior alegria sem dúvida foi a de ter tido a oportunidade de fazer um curso, mesmo que por pouco tempo (1 mês), em Londres. Pude aperfeiçoar a língua e perceber que preciso sempre ainda mais. Meus alunos também são minhas alegrias, pois vejo a cada dia o progresso deles e tento da melhor forma ajudá-los.

Ela menciona ainda que fica muito feliz ao perceber o progresso dos seus alunos no aprendizado da língua inglesa. Ela deixa claro que sua alegria é devida ao fato que busca ajudálos da melhor forma possível.

\section{Experiências e desafios em cursos livres de idiomas} particular:

Ana justifica sua escolha pela oportunidade de ter uma experiência em uma escola

$O * * * * 3$ foi minha primeira experiência na rede privada durante minha graduação, iniciei como prestadora de serviço, fiz o concurso e hoje sou do quadro efetivo da instituição, então um dos motivos porque estou trabalhando na rede privada foi a curiosidade em ter uma experiência na rede privada. (Ana)

João afirma se identificar com o trabalho realizado em cursos livres de idiomas, já que pode utilizar a abordagem comunicativa em suas aulas. É interessante ele dizer que essa abordagem seria inviável em uma escola regular. Percebo sua crença de que em escolas regulares não é possível ensinar línguas de forma interativa. Além disso, ele também declara que não trabalha em escolas públicas por ter críticas em relação ao processo ensinoaprendizagem desenvolvido nesse locus. Entretanto, penso que ele se contradiz ao indicar que poderia vir a trabalhar em uma escola pública futuramente:

Eu trabalho em uma escola particular de idiomas por me identificar com a área e por poder dar aula de língua inglesa em uma abordagem comunicativa e interativa, o que seria inviável em uma escola regular de ensino fundamental ou

${ }^{3}$ Nome de uma escola de idiomas. 
médio. Recentemente, também comecei a trabalhar em uma escola bilíngue em ensino fundamental, o que tem sido uma experiência muito enriquecedora. Não trabalho em escola pública por estar desacreditado desse tipo de ensino e por achar que o custo benefício desse tipo de relação profissional não compensa. No entanto, não descarto a ideia de trabalhar em uma escola pública no futuro. (João)

Antônio manifesta o quanto as experiências vividas durante o estágio impactaram negativamente sua visão sobre o trabalho como professor de inglês em escolas públicas. Ele menciona ter presenciado e sofrido graves problemas de indisciplina durante as aulas em que participou como estagiário. Por outro lado, ele ressalta a importância de conseguir observar o desenvolvimento dos seus alunos em uma escola particular de idiomas:

No momento eu trabalho com alunos em uma escola de idiomas de maneira que consigo observar o seu desenvolvimento. As experiências que tive em escolas públicas foram somente duas, ambas durante a minha graduação, nas disciplinas de "estágio obrigatório", e estas foram verdadeiros desastres. Eu nunca consegui observar o desenvolvimento da língua nos meus alunos, mesmo com o pouco tempo destinado as aulas. Além disso, a desordem era generalizada, o respeito pelo professor estagiário (principalmente no ensino médio) era muitas vezes inexistente e as aulas eram apenas para cumprir tabela. Para mim foi um período profissional muito difícil, do qual tive que refletir se realmente era este o caminho a seguir ou não. E a resposta é não. (Antônio)

Em relação a como se sente como professora em um curso livre de línguas, Ana relata a experiência negativa que teve em uma escola regular particular. Ela ressalta sua insatisfação por não ter liberdade para lecionar conforme desejava, pois tinha que seguir "um padrão préestabelecido) e também critica o fato de haver somente uma aula por semana:

Tive uma experiência no ensino regular da rede privada, e eu achava muito complicado e de certa forma desmotivante, porque eu tive que me adequar "as vontades da escola", ou seja, não tinha liberdade para ministrar minhas aulas utilizando a minha própria didática, pois eu tinha que seguir um padrão pré-estabelecido, eu sentia que minhas aulas era como "um faz de conta", porque era somente uma aula na semana, então tudo era muito corrido.

João diz que se sente muito bem como professor de um curso livre de idiomas porque acredita que seu trabalho é bem realizado e que isso é valorizado pela direção e coordenação da escola. Por outro lado, ele menciona a frustração com o fato do estabelecimento, como mencionado por Freitas (2010), considerar a língua estrangeira um bem de consumo, já que os alunos são vistos como clientes:

Eu me sinto muito bem trabalhando em uma escola particular, pois sinto que meu trabalhado é bem realizado e sou valorizado pela direção e coordenação da escola. Às vezes é frustrante pois o alto poder aquisitivo dos alunos às vezes leva 
a escola a tomar decisões que discordo, mas no mais, eu acho muito positivo. (João)

Antônio expressa sua satisfação como professor de um curso livre de idiomas. Ele justifica isso por se sentir realizado profissionalmente, já que acredita que o desenvolvimento da competência linguística dos alunos pode ser percebido em suas produções orais durante as aulas. Além disso, ele também cita o ambiente agradável e o fato da maioria dos alunos serem educados e motivados a aprender. Ele ainda menciona a disponibilidade de materiais didáticos excelentes:

Em se falando de experiências, eu nunca dei aulas em uma escola regular particular, mas, em contrapartida, já tenho ministrado aulas há quase 6 anos em uma escola de idiomas, e nesta eu me sinto realizado profissionalmente, pois para mim a expressão oral tanto minha quanto dos alunos me leva a crer do aprendizado e me possibilita a medida de desenvolvimento da competência linguística dos alunos. Apesar do pagamento poder ser um pouco melhor, o ambiente é muito agradável, os alunos (em sua grande maioria) são educados, focados e determinados a aprender o idioma e os materiais didáticos são excelentes para os objetivos das aulas. (Antônio)

Ao relatar os desafios enfrentados, Ana somente pensa em sua experiência em uma escola regular particular. Ela cita a desmotivação dos alunos por não se interessarem pela língua e problemas causados pelo número excessivo de alunos na sala de aula, além da já mencionada carga horária insuficiente:

Motivar o aluno a gostar da disciplina e aprender o idioma mesmo com as inúmeras dificuldades que não foram sanadas nos anos anteriores e a superlotação de alunos em uma sala de aula com uma carga horária pequena. (Ana)

João indica que enfrenta desafios como professor de um curso livre de idiomas relacionados à dificuldade em manter a motivação de alunos adultos, tendo em vista que eles têm inúmeras outras preocupações e atividades a desenvolver. Em relação aos adolescentes, ele menciona, além de questões relacionadas à faixa etária, o fato de que alguns são obrigados pelos pais a frequentar as aulas de inglês:

Os maiores desafios são manter os alunos adultos motivados a aprender, pois eles têm outros compromissos como trabalho, família, estudos e nem sempre é fácil conciliar com o inglês. Trabalhar com adolescentes é complicado também porque além das complicações comuns à idade, alguns deles vão às aulas obrigados pelos pais. (João)

Antônio, por sua vez, expressa sua frustração ao ter que ensinar crianças. Ele lastima o fato de não ter aprendido sobre ensino de línguas para crianças no curso de Letras Inglês. 
Ademais, ele revela sua insatisfação com o fato da escola de idiomas onde ele trabalha não investir na formação continuada dos professores, tendo em vista que não há reuniões pedagógicas e que não são discutidas questões voltadas à metodologia de ensino de línguas:

Como principais desafios, eu sinto ainda uma leve frustração ao ter que lidar com o ensino de crianças, por conta de situações que não nos foram ensinadas durante a graduação, como por exemplo, o ensino de inglês para crianças em uma abordagem comunicativa, evidenciando todas as suas necessidades, limitações e interesses, sem mencionar os desafios para com os alunos especiais. Quanto a instituição, os principais desafios são o diálogo dos professores com a coordenação e de professores com professores, pois quase nunca são feitas reuniões ( 1 vez por ano) e as pautas sempre são a respeito dos parâmetros burocráticos da empresa, e nos meus quase 6 anos ministrando aulas, nunca houve uma reunião pedagógica para discussão de estratégias de ensino, ou de novidades para o ensino de crianças, um novo modo de ensinar um conteúdo específico que deu certo em uma turma, entre outros. (Antônio)

Em relação às alegrias vivenciadas como professora de inglês, Ana declara a importância de ter auxiliado um estudante com necessidades especiais e sua satisfação ao ver a turma toda participar ativamente das aulas durante a realização de games:

Ver um aluno portador de necessidade especial devolver habilidades de "speaking" que antes a disciplina era vista por ele como algo sem importância e também motivar a turma toda a participar das aulas através de games que eram utilizados durante a aula. (Ana)

João menciona a realização profissional tanto financeira quanto em relação ao desenvolvimento dos seus alunos, "trabalhar em uma escola particular me satisfaz financeiramente, e a nível profissional é muito bom ver seus alunos progredindo e usando a língua de maneira efetiva".

Antônio afirma que suas maiores alegrias como professor de um curso livre de idiomas ocorrem quando os alunos reconhecem seu trabalho. Ele menciona ter recebido homenagens na escola onde trabalha, com festas de aniversário e de encerramento e postagens em redes sociais. Além disso, ele também mencionou a alegria que sentiu por um aluno ter escolhido cursar Letras Inglês. Ele ressalta sua satisfação por ter influenciado na escolha profissional de um aluno:

As minhas maiores alegrias profissionais são quando os alunos reconhecem o seu esforço e dedicação ao termino de um ciclo, seja um semestre ou um ano letivo, o que já me rendeu homenagens em eventos da instituição, festinhas de encerramento, festas de aniversário surpresa, homenagens nas redes sociais entre outros. Entretanto, um caso bem específico me chama atenção, pois um aluno de inglês intermediário estava cursando o seu último ano de colégio e ainda não tinha decidido qual carreira seguir, e após o 
semestre letivo ele conseguiu decidir por estudar letras-inglês, e eu o reencontrei diversas vezes na universidade. Para mim, saber que fiz parte de uma decisão tão importante na vida de alguém e que fiz a diferença para este aluno a ponto de impulsioná-lo para a profissão docente na área de língua inglesa é motivo de uma satisfação profissional e uma alegria sem tamanho.

\section{Considerações finais}

Tive muita satisfação ao saber que os participantes estão realizando um trabalho muito bem-sucedido nos estabelecimentos de ensino em que estão atuando. Acredito que estamos desempenhando um bom papel na formação inicial de professores de línguas no curso de Letras Inglês da UFPI. É claro que ainda temos muito a melhorar, pois temos muitos desafios a vencer e queremos sempre aperfeiçoar a formação de professores de línguas e desempenhar nosso papel de instituição formadora de profissionais para a comunidade.

Em relação às escolhas dos participantes, tenho a percepção que ocorre um envolvimento um pouco maior nas escolas públicas e que o impacto produzido é um tanto mais relevante nesses locais, tendo em vista, inclusive, a grande necessidade de alunos de comunidades mais carentes. Esses estudantes precisam muito de profissionais responsáveis e cônscios de seu papel no processo de ensino-aprendizagem de línguas.

No entanto, considero que é essencial que o professor se sinta bem onde trabalha. Não questionei os participantes em relação a restrições impostas pelos cursos livres onde lecionam e acredito que essa questão poderia ser pesquisada em trabalhos futuros. Apesar disso, os participantes revelaram sua satisfação profissional e considero esse fato extremamente positivo.

Talvez, futuramente, esses participantes se tornem professores de língua inglesa em escolas públicas e tenham a oportunidade de ressignificar crenças em relação ao insucesso do processo de ensino-aprendizagem de línguas nesses locais.

Espero que, onde quer que estejam trabalhando, continuem buscando seu aperfeiçoamento como professores e que sempre se esforcem para auxiliar seus alunos a atingir seus objetivos em relação à aprendizagem e ao uso da língua inglesa. Precisamos de professores de inglês que percebam a importância da sua atuação para que o quadro de insucessos de aprendizagem da língua, tão observado em inúmeras pesquisas e publicações, seja modificado em um futuro que espero não esteja distante. 


\section{REFERÊNCIAS}

BRITISH COUNCIL - TEACHING ENGLISH. "Learning English in Brazil - Understanding the aims and expectations of the Brazilian emerging middle class". A report for the British Council by the Data Popular Institute. São Paulo: 2014.

CELANI, M. A. A. Ensino de línguas estrangeiras: ocupação ou profissão? In: LEFFA, V. (org.). O professor de línguas: construindo a profissão. Pelotas, p. 21-40, 2001.

COELHO, H. S. H. "É possível aprender inglês na escola?" - Crenças de professores e alunos sobre o ensino de inglês em escolas públicas. Dissertação de Mestrado. Belo Horizonte: Programa de Pós-graduação em Estudos Linguísticos da Faculdade de Letras da Universidade Federal de Minas Gerais, 2005.

FREIRE, P. Carta aos professores. Estudos Avançados, v. 15. n. 4. 2001.

FREITAS, L. M. A. Da fábrica à sala de aula: vozes e práticas tayloristas no trabalho do professor de espanhol em cursos de línguas. Tese de Doutoramento. Doutorado em Letras Neolatinas na Universidade Federal do Rio de Janeiro, 2010.

FULLAN, M. Change forces. Probing the depths of education reform. The Falmer Press, 1993.

GIMENEZ, T. Tornando-se professores de inglês: experiências de formação inicial em um curso de Letras. In: VIEIRA-ABRAHÃO, M. H. (org.) Prática de ensino de língua estrangeira: experiências e reflexões. Campinas: Pontes Editores, 2004.

PAIVA, V. L. M. O. A LDB e a legislação vigente sobre o ensino e a formação de professor de língua inglesa. In: STEVENS, C. M. T.; CUNHA, M. J. Caminhos e colheitas: ensino e pesquisa na área de inglês no Brasil. Brasília: UnB, 2003. Disponível em http://www.veramenezes.com/ensino.htm. Acesso em 15 jul 2017.

PERIN, J. O. R. Ensino/aprendizagem de língua inglesa em escolas públicas: o real e o ideal. In: JORDÃO, C.; GIMENEZ, T.; ANDREOTTI, V. Perspectivas educacionais e o ensino de inglês na escola pública. Pelotas: Educat, p. 143-157, 2005.

SOUZA, C. F. O professor de língua inglesa em cursos de idiomas: uma análise críticoreflexiva do exercício docente nesse "locus" de ensino-aprendizagem de LE/Inglês. Revista Contexturas, n. 21, p. 53-74, 2013.

VAN MANEN, M. Researching lived experience. Human science for an action sensitive pedagogy. London, Ontario, Canada. State University of New York Press, 1990. 


\section{Como referenciar este artigo}

GAMA RODRIGUES, Beatriz. O impacto da formação de professores de inglês realizada na Universidade Federal do Piauí: análise das escolhas profissionais de alguns egressos do curso de Letras Inglês. Rev. EntreLínguas, Araraquara, v. 5, n. 1, p. 210-229, jan./jun. 2019. EISSN: 2447-3529. DOI: 10.29051/el.v5i1.12796

Submetido em: $31 / 03 / 2018$

Aprovado em: 15/06/2019

Publicado em: 30/04/2019 